\title{
Combined 20-gauge and 23-gauge pars plana vitrectomy for the management of posteriorly dislocated lens: a case series
}

This article was published in the following Dove Press journal:

Clinical Ophthalmology

18 June 2010

Number of times this article has been viewed

\author{
Pipat Kongsap \\ Department of Ophthalmology, \\ Prapokklao Hospital, Chanthaburi, \\ Thailand; Affiliated with the Faculty \\ of Medicine, Chulalongkorn University, \\ Bangkok, Thailand
}

Objective: To present a new surgical approach for the management of posteriorly dislocated lens by using a combination of 20 -gauge (20G) and 23-gauge (23G) pars plana vitrectomy.

Design: An interventional case series

Methods: This technique was performed on six patients (five men, one woman; mean age, 66.67 years; range, $66-72$ years). Two $23 \mathrm{G}$ trans-conjunctival sclerotomy ports were created for infusion and illumination along with a $20 \mathrm{G}$ sclerotomy port for introducing the vitrectomy probe or fragmatome.

Results: This procedure was successfully performed on six eyes. On postoperative day one, the media were clear and the retina could be seen by indirect ophthalmoscopy. Hyphema developed in one eye and resolved within a week. There were no observed cases of retinal tear, wound leakage, hypotony, or endophthalmitis. The post-operative follow-up period ranged from three to twelve months (mean, 8.1 months). By the final visit, two patients had achieved a visual acuity of 20/40 or better, three patients, 20/70, and one patient, 20/200.

Conclusion: The combination of $20 \mathrm{G}$ and $23 \mathrm{G}$ pars plana vitrectomy is an efficacious and safe procedure for management of posteriorly dislocated lens.

Keywords: lensectomy, fragmatome, sutureless vitrectomy

\section{Introduction}

The 23-gauge $(23 \mathrm{G})$ sutureless vitrectomy technique is becoming increasingly popular because of the decreased surgical trauma, faster wound healing, and improved postoperative comfort associated with this technique. Because small surgical incisions do not require sutures, the operation times for $23 \mathrm{G}$ sutureless vitrectomy and the postoperative inflammation are reduced, and patient recuperation is more rapid. ${ }^{1-5}$

Fragmatomes are not yet available in a $23 \mathrm{G}$ version; therefore, I introduced a new technique that combines $23 \mathrm{G}$ and 20 -gauge (20G) vitrectomy and lensectomy for the management of posteriorly dislocated lens and dropped nuclei.

\section{Materials and methods}

This prospective study was conducted on 6 eyes of 6 patients who were diagnosed with posteriorly dislocated lens and underwent pars plana vitectomy between May 2008 and April 2009 at the Department of Ophthalmology, Prapokklao Hospital. After all the patients were given detailed explanations of the procedure and its potential benefits and risks, informed consent was obtained from them. Each patient underwent a complete preoperative ophthalmic examination, which included measurement of the
Correspondence: Pipat Kongsap,

Department of Ophthalmology, Prapokklao Hospital, Chanthaburi 22000, Thailand

Tel + $6639324975($ ext 1450)

Fax + 6639324861

Email pkongsap@yahoo.com;

pkongsap@gmail.com 
best corrected visual acuity (BCVA) using a standard Snellen chart, a slit-lamp examination, applanation tonometry, and dilated fundus examination.

\section{Surgical technique}

Two 23G transconjunctival sclerotomy ports were created for infusion and illumination (Alcon Laboratories Inc., Fort Worth, TX, USA), and a third 20G sclerotomy port was created for introducing the vitrectomy probe. To create the $23 \mathrm{G}$ port, the conjunctiva was displaced by approximately 1-3 $\mathrm{mm}$ with a pressure plate. A $23 \mathrm{G}$ trocar-cannula was first inserted through the conjunctiva and sclera, parallel and $3.5 \mathrm{~mm}$ posterior to the limbus, and then at an angle of approximately $5^{\circ}$ until it just passed the end of the bevel. At that point, the handle was raised slightly to an angle of approximately $30^{\circ}$ and the cannula was then inserted into the hub. The trocar was removed while the cannula was stabilized with forceps. The third port was created via a localized peritomy and sclerotomy with a $20 \mathrm{G}$ microvitreoretinal blade. The vitrectomy probe or fragmatome was introduced through the $20 \mathrm{G}$ port. A complete vitrectomy was performed before the trans pars plana lensectomy in order to remove vitreous traction from the lens. The fragmatome was set at an ultrasound power of $30 \%-50 \%$ and a vacuum of $100-150 \mathrm{mmHg}$. Increasing the infusion pressure from $35 \mathrm{mmHg}$ to $50 \mathrm{mmHg}$ ensured the prevention of intraoperative hypotony. Modified 4-point scleral fixation of intraocular lenses (IOLs) ${ }^{6-7}$ was also performed on five eyes with trauma. Plugs were placed in the cannula, which was removed at the end of the surgery by applying gentle traction with the help of forceps. The displaced conjunctiva was repositioned with a cotton swab or smooth forceps while the single $20 \mathrm{G}$ opening was sutured with 7-0 Vicryl. Care was taken to examine for sclerotomy leakage at physiological pressure.

Intraoperative indirect ophthalmoscopy was also performed on all patients in order to examine their peripheral retina. Complete ophthalmic examinations, which included measurement of the BCVA, slit-lamp biomicroscopy, tonometry, and dilated fundus examination, were performed one day, one week, one month, six months and one year after the operation.

\section{Results}

This above surgical procedure was successfully performed on six eyes of six patients. The preoperative data are summarized in Tables 1 and 2. Five of these patients were referred to my hospital for the treatment of traumatic posterior dislocation of the lens, whereas the sixth had experienced lens dislocation after cataract extraction by phacoemulsification. Perfluorocarbon liquid (PFO) was used for retinal protection in the five patients with crystalline lens. Phacofragmentation was safely performed in the sixth patient without the use of PFO. Of the five patients with traumatic dislocation, one (case 2) presented with lattice degeneration and a small retinal hole; these were treated using endolaser photocoagulation. The retina was flat intraoperatively and postoperatively.

On postoperative day one, the media were clear and the retina could be seen by indirect ophthalmoscopy. Hyphema developed in one eye and resolved within a week. There were no observed cases of retinal tear, wound leakage, hypotony, or endophthalmitis. The duration of the postoperative follow-up ranged from three to twelve months (mean, 8.1 months). By the final visit, two patients had achieved a visual acuity of 20/40 or better and three patients, 20/70. One patient (case 2) had a history of secondary glaucoma and achieved a postoperative visual acuity of only 20/200. One patient developed cystoid macular edema, which partially resolved with medical treatment. Retinal detachment was not detected during the follow-up period.

\section{Discussion}

A posteriorly dislocated lens after intraocular surgery or blunt eye trauma is an uncommon event, and is associated with complications such as intraocular inflammation, corneal edema, elevated intraocular pressure, retinal detachment, and vitreous hemorrhage. ${ }^{8}$ In cases of partial lens dislocation associated with traumatic zonular dialysis of less than $160^{\circ}$, implantation of a capsular tension ring (CTR) before or

Table I Patients who underwent combined 20G and 23G pars plana vitrectomy/lensectomy

\begin{tabular}{llllllll}
\hline Patient & Age & Gender & Lesion & Cause & Diagnosis & Preop BCVA & Postop BCVA \\
\hline I & 66 & M & OD & Trauma & PDL & CF/30 cm & $20 / 40$ \\
2 & 72 & F & OS & Trauma & PDL, G & $3 / 200$ & $20 / 200$ \\
3 & 72 & M & OD & Trauma & PDL, Uveitis & CF $/ 20 \mathrm{~cm}$ & $20 / 70$ \\
4 & 66 & M & OS & Trauma & PDL, VH & $\mathrm{HM} / 10 \mathrm{~cm}$ & $20 / 70$ \\
5 & 65 & M & OS & Trauma & PDL & CF $/ 30 \mathrm{~cm}$ & $20 / 30$ \\
6 & 65 & F & OS & Cataract & Dropped nucleus & $9 / 200$ & $20 / 70$ \\
\hline
\end{tabular}

Abbreviations: OD, oculus dexter; OS, oculus sinister; PDL, posteriorly dislocated lens; G, glaucoma; VH, vitreous hemorrhage; BCVA, best-corrected visual acuity; CF, count fingers; HM, hand motion; M, male; F, female. 
Table 2 Preoperative ocular findings

\begin{tabular}{|c|c|c|}
\hline Patient & $\begin{array}{l}\text { Anterior segment finding pupils/iris } \\
\text { capsule/zonule }\end{array}$ & Posterior segment finding \\
\hline I & $3 \mathrm{~mm}$, round, $360^{\circ}$ zonular dialysis & $\begin{array}{l}\text { No vitreous hemorrhage, crystalline lens in posterior } \\
\text { vitreous cavity, no retinal break }\end{array}$ \\
\hline 2 & $3 \mathrm{~mm}$, iridodialysis, $360^{\circ}$ zonular dialysis & $\begin{array}{l}\text { No vitreous hemorrhage, crystalline lens in posterior } \\
\text { vitreous cavity, lattice degeneration with a small retinal hole }\end{array}$ \\
\hline 3 & $2 \mathrm{~mm}$, round, iris hole, $360^{\circ}$ zonular dialysis & $\begin{array}{l}\text { Haziness of vitreous gel, crystalline lens in posterior } \\
\text { vitreous cavity, no retinal break }\end{array}$ \\
\hline 4 & $2 \mathrm{~mm}$, round, $300^{\circ}$ zonular dialysis & $\begin{array}{l}\text { Vitreous hemorrhage, crystalline lens in anterior vitreous } \\
\text { cavity, no retinal break }\end{array}$ \\
\hline 5 & $2 \mathrm{~mm}$, round, $360^{\circ}$ zonular dialysis & $\begin{array}{l}\text { No vitreous hemorrhage, crystalline lens in posterior } \\
\text { vitreous cavity, no retinal break }\end{array}$ \\
\hline 6 & $\begin{array}{l}2 \mathrm{~mm} \text {, round, } \mathrm{P} / \mathrm{C} \text { tear, intact anterior } \\
\text { capsular ring, } \mathrm{IOL} \text { in the sulcus }\end{array}$ & $\begin{array}{l}\text { No vitreous hemorrhage, } 80 \% \text { of crystalline lens in vitreous } \\
\text { cavity, no retinal break }\end{array}$ \\
\hline
\end{tabular}

Abbreviation: $\mathrm{P} / \mathrm{C}$, posterior capsule.

during phacoemulsification with an in-the-bag posterior chamber (PC) IOL is a relatively safe technique with a high success rate. The CTR is efficient in preventing IOL dislocation in eyes with traumatic zonular deficiency. ${ }^{9}$ For severe lens instability with a zonular dialysis greater than $180^{\circ}$ and complete lens dislocation, a pars plana approach should be considered. ${ }^{10}$

It is clear that $20 \mathrm{G}$ pars plana vitrectomy and lensectomy are the best methods for the management of posterior dislocation of the lens and the resultant complications, in particular, uveitis, glaucoma, and retinal detachment. The ultimate goal of a vitreoretinal surgeon is to remove the retained lens material while avoiding vitreous traction and retinal injury.

The $23 \mathrm{G}$ sutureless vitrectomy technique is becoming increasingly popular and the indications for this technique have expanded to include conditions such as non-clearing vitreous hemorrhage, epiretinal membrane, macular holes, vitreomacular traction, and intraocular foreign body. Generally, posteriorly dislocated lens or dropped nucleus are contraindications for this sutureless technique. ${ }^{11}$ This is because some vitrectomy tools such as the ultrasonic fragmatome are currently not available in a $23 \mathrm{G}$ version. In this study, I used a combination of $20 \mathrm{G}$ and $23 \mathrm{G}$ sclerotomies and instruments. This combination technique has previously been successfully used in cases of epiretinal membrane, macular holes, diabetic vitreous hemorrhage, and tractional retinal detachment. ${ }^{12}$

To the best of my knowledge, there are no reports in the literature on the combined use of $23 \mathrm{G}$ and $20 \mathrm{G}$ vitrectomy with lensectomy for the management of patients with posteriorly dislocated lens and dropped nucleus. With regard to retained lens fragments, cortical and small nuclear fragments may be removed using a $23 \mathrm{G}$ cutter. Large or hard fragments are removed using a $20 \mathrm{G}$ fragmatome.
In this study, both vitrectomy and lensectomy were successfully performed on all six eyes without any complications. Intra-operative hypotomy can occur during lensectomy because of fluid leakage through the $20 \mathrm{G}$ opening. To prevent this, I increased the infusion pressure from $35 \mathrm{mmHg}$ to $50 \mathrm{mmHg}$ and decreased the maximum fragmatome vacuum. Another problem with this technique (during the vitrectomy or lensectomy) is the difficulty in interchanging hands if the second superior port needs to be enlarged. However, for all subjects in this study, conversion of the second port to $20 \mathrm{G}$ sclerotomy was not required.

The major limitations of this study are the small sample size and short follow-up period. For more accurate conclusions, studies with a larger sample size and longer follow-up should be performed.

In conclusion, the combined $20 \mathrm{G}$ and $23 \mathrm{G}$ vitrectomy with lensectomy can be used as an alternative method for the management of posteriorly dislocated lens and dropped nucleus as the $23 \mathrm{G}$ fragmatome is not yet available. Furthermore, the single-suture $20 \mathrm{G}$ sclerotomy in this technique may help shorten the surgical opening and closing times.

\section{Acknowledgments and disclosure}

The author has no financial or proprietary interest in the products mentioned in this article. The author wishes to thank Editage (www.editage.com) for editing the manuscript.

\section{References}

1. Wimpissinger B, Kellner L, Brannath W, et al. 23-Gauge versus 20-gauge system for pars plana vitrectomy: a prospective randomised clinical trial. Br J Ophthalmol. 2008;92(11):1483-1487.

2. Eckardt C. Transconjunctival sutureless 23-gauge vitrectomy. Retina. 2005;25(2):208-211.

3. Nagpal M, Wartikar S, Nagpal K. Comparison of clinical outcomes and wound dynamics of sclerotomy ports of 20, 25, and 23 gauge vitrectomy. Retina. 2009;29(2):225-231. 
4. Chieh JJ, Rogers AH, Wiegand TW, Baumal CR, Reichel E, Duker JS. Short-term safety of 23-gauge single-step transconjunctival vitrectomy surgery. Retina. 2009;29(10):1486-1490.

5. Fine HF, Iranmanesh R, Iturralde D, Spaide RF. Outcomes of 77 consecutive cases of 23-gauge transconjunctival vitrectomy surgery for posterior segment disease. Ophthalmology. 2007;114(6):1197-1200.

6. Chakrabarti A, Gandhi RK, Chakrabarti M. Ab externo 4-point scleral fixation of posterior chamber intraocular lenses. J Cataract Refract Surg. 1999;25(3):420-426.

7. Baykara M, Avci R. Prevention of suture knot exposure in posterior chamber intraocular lens implantation by 4-point scleral fixation technique. Ophthalmic Surg Lasers Imaging. 2004;35(5):379-382.

8. Blodi BA, Flynn HW Jr, Blodi CF, Folk JC, Daily MJ. Retained nuclei after cataract surgery. Ophthalmology. 1992;99(1):41-44.
9. Georgopoulos GT, Papaconstantinou D, Georgalas I, Koutsandrea CN, Margetis I, Moschos MM. Management of large traumatic zonular dialysis with phacoemulsification and IOL implantation using the capsular tension ring. Acta Ophthalmol Scand. 2007;85(6):653-657.

10. Salehi-Had H, Turalba A. Management of traumatic crystalline lens subluxation and dislocation. Int Ophthalmol Clin. 2010;50(1):167-179.

11. Fine HF, Bhatnagar P, Spaide R. 23- gauge vitrectomy. In Bhavsar AR, editors. Surgical techniques in ophthalmology: retina and vitreous surgery. China: Saunders Elsevier, China. 2009:51-58.

12. Kumar A, Kakkar A, Jindal S, Rajesh R. Combination 20 and 23-gauge transconjunctival vitrectomy: a new approach. Indian J Ophthalmol. 2009;57(6):459-461.
Clinical Ophthalmology

\section{Publish your work in this journal}

Clinical Ophthalmology is an international, peer-reviewed journal covering all subspecialties within ophthalmology. Key topics include: Optometry; Visual science; Pharmacology and drug therapy in eye diseases; Basic Sciences; Primary and Secondary eye care; Patient Safety and Quality of Care Improvements. This journal is indexed on

\section{Dovepress}

PubMed Central and CAS, and is the official journal of The Society of Clinical Ophthalmology (SCO). The manuscript management system is completely online and includes a very quick and fair peer-review system, which is all easy to use. Visit http://www.dovepress.com/ testimonials.php to read real quotes from published authors. 